\title{
PESQUISA JUNTO A MÃES ACOMPANHANTES: REFLEXÕES SOBRE OS RESULTADOS OBTIDOS
}

\author{
Edelia del Pilar Neira Huerta*
}

NEIRA HUERTA, E. del P. Pesquisa junto a mães acompanhantes: reflexões sobre os resultados obtidos. Rev. ESc. Enf. USP, São Paulo, 19(3):225-229, 1985.

A autora apresenta suas reflexōes sobre os resultados obtidos em sua pesquisa junto a mães acompanhantes, as quais incluem aspectos de assistência $e$ de ensino-liprendizagem.

Com a finalidade de encontrar elementos que permitam melhorar a assistência à mãe acompanhante em nosso meio, enquanto aluna do Curso de Mestrado realizei um estudo procurando saber o que as mães em situação de acompanhante hospitalar de um filho doente sentem, o que precisam e o que esperam da equipe hospitalar, bem como as razões dessas mães para seus sentimentos, necessidades e expectativas.

Os resultados obtidos nesse estudo (NEIRA HUERTA ${ }^{1,2}$ ) permitiram-me verificar que:

- as mães acompanhantes sentem mais mal-estar do que bem-estar no hospital, mal-estar esse que elas justificam principalmente através de uma gama de motivos relacionados à situação hospitalar;

- a principal necessidade das mães na situação estudada é dar cuidado ao filho, além de necessidades relacionadas com informações sobre a doença do filho, com conforto físico e com a recuperação da saúde do filho;

- as mães acompanhantes esperam contatos pessoais da equipe hospitalar e que o pessoal hospitalar dê assistência às crianças.

Pude constatar também a existência de enorme variedade de motivos determinando tanto as necessidades quanto as expectativas das mães acompanhantes que fizeram parte do estudo.

Esses resultados, que evidenciaram claramente a individualidade das mães e dos significados que a experiência de acompanhar um filho hos-

* Enfermeira. Mestre em Enfermagem. Docente do Departamento de Enfermagem MaternoPediátrica. 
pitalizado têm para cada uma delas, fazem-me sentir que encontrei alguns dos elementos que buscava quando me propus a realizar esse estudo.

Embora as mães acompanhantes se sintam de maneira similar no hospital e apresentem necessidades e expectativas semelhantes, os motivos que determinam cada um desses aspectos são diferentes e únicos para cada mãe. Pode-se compreender, assim, a necessidade de se conhecer e compreender esses motivos individuais se quisermos ser efetivos ao prestar-lhes assistência.

Esses resultados mostram, portanto, ser necessário perceber as mães acompanhantes de maneira holística, lembrando sempre que cada mãe tem um sentir, um pensar e um querer próprios e únicos, resultado tanto de suas experiências passadas e atuais como de seus planos para o futuro, e não, percebê-las apenas como alguém cuja presença ajuda à criança no hospital e que deve ser assistido, para, dessa maneira, garantir a segurança, o desenvolvimento e o bem-estar da criança.

Esses resultados ajudam a compreender que assistência efetiva às mães acompanhantes é aquela individualizada, centrada na pessoa de cada mãe e resultante tanto da compreensão empática da mãe e de sua realidade como de ações condizentes com essa compreensão.

Tenho agora, a certeza de que não existe uma "receita" ou padrão de assistência a ser seguido. Ao contrário, nossas ações deverão ser o resultado da aproximação, do contato pessoal e da interação efetiva com cada mãe acompanhante, em um processo sempre a se renovar. Será através desta interação, e na medida em que pudermos conhecer e compreender como a mãe se sente no hospital, do que ela precisa e o que espera e, principalmente, o porquê de cada um desses aspectos, que obteremos as "dicas" necessárias para planejar e implementar ações adequadas; estas ações permitirão contribuir para seu bem-estar e atender de maneira efetiva suas necessidades e expectativas. Não tenho dúvidas ao acreditar que apenas o fato de se aproximar delas demonstrando nosso interesse e vontade de ajudá-las, favorecerá, e muito, seu bem-estar no hospital.

Aprendi que, para interagir efetivamente com alguém - a mãe acompanhante, no caso - e conseqüentemente para compreendê-lo, é necessário sentir interesse verdadeiro por ele e querer estabelecer contato com o mesmo; é necessário aceitá-lo sem julgamentos, respeitando-o e confiando nele. Aprendi, também, que são necessárias habilidades de comunicação, não apenas para comunicar nossos próprios sentimentos e vontades, de maneira que sejam percebidos pelo outro, mas, também, e principalmente, ter habilidade para ajudá-lo a se comunicar e para ouvir e captar aquilo que ele nos comunique com ou sem palavras.

Essas considerações, junto com algumas atitudes e comportamentos da equipe hospitalar, mencionados no estudo (NEIRA HUERTA ${ }^{1}$ ), tornam evidente a urgente necessidade de se mudar atitudes, bem como de se adquirir habilidades que permitam ao pessoal hospitalar interagir 
efetivamente com as mães acompanhantes e, conseqüentemente, prestar-lhes a assistência de que elas realmente necessitem.

Reconhecendo que a assistência às mães acompanhantes não é responsabilidade de apenas alguns membros da equipe de saúde, mas que todos seus integrantes devem contribuir para a criação de um clima de bem-estar para as mães, e que todos seus membros podem e devem ajudar de alguma forma, ainda que pareça insignificante, no atendimento das necessidades e expectativas das mães acompanhantes, gostaria de ver minhas colegas de profissão tomando a iniciativa nessas mudanças e aquisições, e mais tarde, vê-las tentando facilitar essas modificaçōes para o resto da equipe.

Como caminhos que poderiam ajudar as enfermeiras nessas mudanças imagino, em primeiro lugar, a sua vivência de interações pessoais com as mães acompanhantes, isto é, as enfermeiras se aproximando das mães, iniciando o contato com elas, se percebendo e percebendo a pessoa da mãe, tentando constantemente conhecê-la e compreendê-la. Acredito que, a cada nova experiência, alargar-se-á sua percepção, sua tolerância e aceitação do comportamento humano, assim como sua capacidade de compreensão empática também aumentará.

Vejo nessas vivências a oportunidade de descobertas pessoais: cada enfermeira descobrindo as atitudes que facilitam seu relacionamento com as mães, como também aquelas que o dificultam; descobrindo aquilo que ela é e definindo aquilo que ela quer ser junto às mães.

Pessoalmente, tenho plena certeza de que quero ser para as mães acompanhantes, uma pessoa que lhes facilite a obtenção de crescimento pessoal na experiência de acompanhar um filho doente no hospital. Aprendi que, para isto, é necessário ajudá-las a utilizar suas potencialidades, tanto para enfrentar suas dificuldades, para aceitar suas limitações e reconhecer suas forças e capacidades, como para encontrar recursos próprios - ou encontrar e utilizar recursos externos quando necessário - que a ajudem a manter sua integridade durante a experiência.

Acredito que perguntas como as utilizadas em minha pesquisa (NEIRA HUERTA ${ }^{1}$ ) poderão ajudar as enfermeiras - e outros membros da equipe - a se aproximar e a estabelecer contato com as mães e, se forem verdadeiras em sua aproximação, servir-lhes-ão também, como veículo para demonstrar às mães seu interesse, preocupação, disponibilidade e vontade de lhes prestar ajuda; as mesmas perguntas poderão facilitar-lhes a obtenção de "dicas", para uma intervenção efetiva de enfermagem. Penso, também, que as recomendações dos diferentes autores que se preocupam com a presença da mãe no hospital, algumas das quais foram mencionadas no trabalho (NEIRA HUERTA ${ }^{1}$ ), serlhes-ão de grande utilidade como ponto de partida.

Vejo um outro caminho, complemento do primeiro, para facilitar a consecução das mudanças desejadas e necessárias, no compartilhar das vivências junto às mães em uma atmosfera de abertura, não avaliadora, 
mas de contribuições mútuas, onde cada um se sinta aceito e livre para falar de seus sentimentos e emoçóes, para expôr suas necessidades c vontades em relação à presença da mãe na unidade pediátrica.

Acredito que este compartilhar de vivências poderia ser mais fácil se ocorresse, primeiro, apenas entre enfermeiras e, mais tarde, se estendesse gradativamente aos outros profissionais e membro da equipe.

Sem dúvida, um caminho que facilitaria essa troca de experiências e que também traria as mudanças de percepção, atitudes e comportamentos, bem como a aquisiçãão de habilidades de comunicação necessárias à assistência efetiva às mães acompanhantes seria a realização de pesquisa participante sobre o assunto junto a toda a equipe hospitalar.

Acredito que, como conseqüência dessas vivências junto às mães, particularmente quando compartilhadas, cada enfermeira, cada membro da equipe aprenderá, não apenas a aceitar as mães e seus colegas, mas também a aceitar suas próprias forças e fraquezas. Cada um se conhecerá e compreenderá melhor, na medida em que conheça e compreenda as mães acompanhantes e seus colegas de equipe.

Gostaria, também, de que todos os futuros enfermeiros tivessem oportunidade, ainda como estudantes, de descobrir os elementos necessários a uma assistência efetiva às mães acompanhantes, aos pais de crianças hospitalizadas. Gostaria que eles tivessem oportunidade de modificar sua percepção, suas atitudes e seus comportamentos em relação às mães acompanhantes quando eles sentissem essas mudanças como necessidades próprias e tivesem vontade de mudar.

Sinto que ajudo meus alunos a aprender a prestar assistência aos pais - a aprender enfermagem pediátrica - quando consigo criar para eles um clima que lhes facilite a vivência de experiências significativas junto aos pais de crianças hospitalizadas; quando eles percebem que os aceito e respeito, que confio neles, em sua responsabilidade e potencialidades; quando eles percebem meu esforço e disposição constantes para ouví-los e compreendê-los e percebem que me interesso por eles e quero ajudá-los a aprender - aprendendo junto com eles e compartilhando com eles todas suas experiências.

Sei que, quando os estudantes percebem esse clima e se sentem livres para aprender, eles começam a se perceber junto aos pais, às crianças e aos diferentes membros da equipe e verbalizam, sem medo, suas percepções e emoções. Começam, então, a apresentar um comportamento ativo, uma procura constante dos mais variados recursos, e a desenvolver sua criatividade e suas capacidades. Eles trocam, analisam e compreendem a essência de suas experiências, descobrindo, então, a enfermagem que eles querem praticar e os enfermeiros que eles querem vir a ser. Sei, portanto, que eles aprendem, crescem e se fortalecem como futuros profissionais, quando se descobrem e se aceitam como pessoas e quando sua aprendizagem abrange seus sentimentos, suas idéias e suas vontades. 
Em outras palavras, acredito que os estudantes aprendem a se relacionar significativamente com as mães acompanhantes, e com qualquer pessoa - aprendizado este que sinto e considero como essencial à assistência efetiva de enfermagem - através de relacionamentos com professores, que lhes permita sentir-se aceitos e valorizados; com adultos capazes de compreendê-los e que lhes comuniquem de maneira efetiva sua compreensão.

Os resultados do meu estudo me levaram, também, a lembrar e refletir sobre outras situações de assistência em saúde - tanto em aspectos de recuperação como de prevenção e manutenção - das quais, de alguma forma, participei. Essas lembranças me levam a sentir e pensar que os resultados obtidos na minha pesquisa, ou seja, o que as mães acompanhantes sentem no hospital e aquilo de que elas necessitam e esperam da equipe hospitalar, são comuns aos clientes nessas diferentes situaçōes em que a intenção é dar assistência para à saúde e, sinto-me inclinada a acreditar que os motivos dessas pessoas - clientes - da mesma forma que os apresentados pelas mães que fizeram parte deste estudo — são, também, de uma grande variedade.

Gostaria que estas reflexões servissem para outros profissionais e membros da equipe de saúde, particularmente para as enfermeiras e docentes de enfermagem, como um convite à reflexão sobre sua atividade profissional.

NEIRA HUERTA, E. del P. Research by rooming-in mothers: reflections upon the results Rev. Esc. Enf. USP, São Paulo, 19(3):225-229, 1985.

The author presents her reflections upon the results she obtained in research by rooming-in mothers, in which assistance and teaching - learning aspects are included.

\section{REFERENCIAS BIBLIOGRÁFICAS}

1. NEIRA HUERTA, E. del P. A experiência de acompanhar um filho hospitalizado: sentimentos, necessidades e expectativas manifestados por mães acompanhantes. São Paulo, 1984. 218 p. (Dissertaçăo de Mestrado - Escola de Enfermagem da USP).

2. NEIRA HIJERTA, E. del P. A experiência de acompanhar um filho hospitalizado: sentimentos, necessidades e expectativas manifestados por mães acompanhantes - resumo. Rev. Fac. Fuf. USP, São Paulo, 19(2):153-171, 1985. 